\title{
Biotecnología para la producción masiva de juveniles del botete diana Sphoeroides annulatus: inducción hormonal y cultivo larvario
}

Biotechnology for the mass production of juvenile bullseye puffer fish Sphoeroides annulatus: hormonal induction and larval rearing

\section{María Isabel Abdo de la Parraํㅜ, L. Estela Rodríguez-Ibarra1, Noemí García-Aguilar', Gabriela Velasco-Blanco $^{1}$ y Leonardo Ibarra-Castro ${ }^{1}$}

\begin{abstract}
${ }^{1}$ Centro de Investigación en Alimentación y Desarrollo, A. C., Unidad Mazatlán Av. Sábalo Cerritos s/n, CP. 82010, Mazatlán, Sinaloa, México. abdo@ciad.mx

Abstract.- The bullseye puffer fish Sphoeroides annulatus is an important marine species due to its culture potential and high market value in Mexico. Research on aspects of reproduction and larvae culture of this puffer fish commenced in México in 1997 at Centro de Investigación en Alimentación y Desarrollo (CIAD-Mazatlan Unit), Mazatlán, Sinaloa. This work describes the following biotechnological developments for obtaining mass production of the bullseye puffer fish juveniles: hormonal induction methods, spawning, egg fertilization and incubation, culture of live feed and larviculture.
\end{abstract}

Key words: Bullseye puffer fish, Sphoeroides annulatus, biotechnology, larviculture

Resumen.- El botete diana Sphoeroides annulatus es un pez marino con alto valor en el mercado mexicano con potencial para su cultivo. Las investigaciones sobre los aspectos reproductivos y cultivo de larvas de esta especie, iniciaron en México a partir de 1997 en el Centro de Investigación y Alimentación (CIAD), Unidad Mazatlán. El presente trabajo describe el desarrollo de la biotecnología para la producción masiva de juveniles; la cual incluye los protocolos para la inducción hormonal, desove, fertilización e incubación de huevos, cultivo de alimento vivo y cultivo de larvas.

Palabras clave: Botete diana, Sphoeroides annulatus, biotecnología, larvicultura

\section{INTRODUCCIÓN}

México es un país que tiene un enorme potencial para el cultivo de peces marinos; cuenta con especies con un alto valor comercial y con condiciones medioambientales apropiadas para desarrollar una maricultura sustentable. Sin embargo, hasta la fecha sólo el cultivo de camarón y de algunos moluscos se realizan a escala comercial. En cuanto al cultivo de peces marinos en el litoral del Pacífico se han desarrollado recientemente algunas biotecnologías para la producción de juveniles para su engorda en jaulas como es el caso del botete diana Sphoeroides annulatus (Jenyns, 1842), una especie que se distribuye desde San Diego, CA hasta Perú. Las especies del género Sphoeroides poseen un cuerpo alargado, grueso, robusto y relativamente suave. Su nombre común se debe a los patrones característicos en la piel de la especie que simulan un blanco de tiro (dianas) (Thomson et al. 2000). Se localizan en la zona costera, principalmente en zonas protegidas, estuarios, lagunas costeras y otras áreas salobres; así como sobre corales y en interfaces rocoso arenosas. Es una especie fecunda que se reproduce a finales de la primavera en zonas cercanas a la costa (Amezcua-Linares 1996). Son preferentemente carnívoros y contienen una toxina llamada tetrodotoxina, que se encuentra principalmente en el hígado (Mallard et al. 1982, Nuñez-Vázquez et al. 2000). Son organismos gonocóricos (sexos separados), la fecundación es externa y los huevos fertilizados son esféricos, demersales y adhesivos (Abdo de la Parra et al. 2001, Martínez-Palacios et al. 2002, Duncan et al. 2003).

El botete diana presenta varios aspectos biológicos favorables para la acuicultura, es un pez que se adapta a distintas condiciones ambientales, es eurihalino, de fácil adaptación al cautiverio y manejo (Abdo-de la Parra \& Duncan 2002, Duncan \& Abdo de la Parra 2002, Duncan et al. 2003). Es una especie muy apreciada en el mercado nacional, ya que posee un filete blanco, de excelente sabor, buena consistencia, sin espinas y con un alto valor comercial, su filete alcanza costos hasta de 110,00 pesos $\mathrm{kg}^{-1}$. Por todas estas características, se ha considerado como una especie apropiada para la acuicultura. Sin 
embargo, la principal limitante que se presenta en el desarrollo del cultivo de peces marinos es la reproducción controlada y el cultivo de larvas para poder obtener una fuente confiable de juveniles para su engorda (Tucker 1998). El desarrollo de la biotecnología de cultivo a escala experimental del botete diana se inició a finales de los 90 en el Centro de Investigación de Alimentación y Desarrollo (CIAD), Unidad Mazatlán. En la actualidad se cuenta con la biotecnología a escala piloto para la producción de juveniles. El presente trabajo describe el conocimiento actual sobre los principales aspectos reproductivos y cultivo de larvas del botete diana obtenidos a lo largo de 16 años de investigación en la planta piloto de producción de juveniles de peces marinos del CIAD, Unidad Mazatlán.

\section{REPRODUCTORES}

El banco de reproductores se formó a partir de individuos capturados en el medio natural en los meses de febrero a junio cuando migran para desovar en aguas cercanas a la costa y en lagunas costeras. Se capturaron por medio de anzuelos (pesca artesanal), en la boca del estero de Teacapán, Sinaloa y se transportaron a las instalaciones de investigación del CIAD, Unidad Mazatlán. Antes de colocarlos en los tanques de aclimatación se sometieron a tratamientos de agua dulce para disminuir o eliminar la gran diversidad de parásitos que presentan. A este respecto, se han logrado avances muy significativos en cuanto a la identificación y control de los parásitos que presenta el botete diana (Fájer \& Chávez, 1999, Ho et al. 2001, Fájer et al. 2003, 2004, 2008, 2011). En los primeros años de experimentación, el lote de reproductores se mantenía bajo condiciones ambientales en tanques circulares de fibra de vidrio de $3 \mathrm{~m}^{3}$ con flujo constante de agua $\left(400 \%\right.$ volumen dia $\left.{ }^{1}\right)$ filtrada a $20 \mu \mathrm{m}$. Se alimentaban 2 veces al día, el 50\% de la ración con un alimento comercial para trucha (El Pedregal, Silver Cup, Toluca México) y el otro 50\% con un alimento balanceado elaborado en CIAD, basado en los requerimientos nutricionales del botete tigre (Kanasawa 1991, Abdo de la Parra \& Duncan, 2002, Duncan \& Abdo 2002, Duncan et al. 2003, Martínez-Chávez et al. 2003, Komar et al. 2004). Actualmente, el lote de reproductores está formado por ejemplares silvestres adaptados al cautiverio y por peces nacidos en cautiverio criados para este fin (generaciones F1 y F2), que se mantienen en tanques circulares de fibra de vidrio de $7 \mathrm{~m}^{3}$, con aireación y flujo de agua constante, con fotoperiodo y temperatura ambiental. Se alimentan con una mezcla a base de alimento fresco compuesto de pescado, camarón y calamar y alimento comercial para reproductores (INVE Fish Breed) al 3\% de su biomasa (Álvarez-Lajonchere et al. 2008, García Aguilar et al. 2009).

\section{INDUCCIÓN HORMONAL}

El primer desove exitoso se obtuvo en 1997 de una hembra madura recién capturada del medio natural, tras presión abdominal para obtener los ovocitos, que fueron fertilizados artificialmente con esperma obtenido de 2 machos silvestres maduros también recién capturados en la costa cercana a Mazatlán, Sin. (Martínez-Palacios et al. 2002). A partir de entonces se inició la investigación para lograr la maduración del botete diana en cautiverio.

\section{Machos}

Rodríguez-Montes de Oca (2001) evaluó el efecto de la hormona LHRHa en la calidad del esperma de $S$. annulatus, reportando que el volumen espermático aumenta significativamente al aplicar la hormona, sin afectar la calidad del esperma. Sin embargo, los mismos autores demostraron que los machos sin inducir maduran en cautiverio y producen suficiente volumen para fertilizar varios desoves; por lo tanto, para reducir costos, actualmente los machos del lote de reproductores del CIAD no son inducidos hormonalmente para su reproducción, sólo se seleccionan los machos que presenten esperma con un porcentaje mínimo de motilidad del 90\% y un tiempo promedio de duración de actividad de 150 s (Abdo-de la Parra et al. 2010, Rodríguez-Ibarra et al. 2010a, 2011).

\section{HEMBRAS}

El primer protocolo desarrollado en el CIAD para la inducción hormonal de las hembras en cautiverio constaba de 2 inyecciones intramusculares de la hormona LHRHa, la primera de $20 \mu \mathrm{mgg}^{-1}$ y la segunda de $40 \mu \mathrm{m}$ $\mathrm{kg}^{-1} \mathrm{o}$ de la aplicación de implantes intramusculares de liberación rápida EVACs (Ethylene-Vinyl Acetate copolymer, University of Maryland Biotechnology Institute, Centre of Marine Biotechnology Baltimore,MD, USA) de la misma hormona, ambos métodos mostraron buenos resultados (Duncan et al. 2003). Posteriormente se evaluó la aplicación del implante vía intraperitoneal (García-Aguilar et al. 2009) un procedimiento que mejora significativamente el porcentaje de eclosión y tamaño de la larva recién eclosionada. A partir de entonces, este protocolo es el que se utiliza para inducir a las hembras de $S$. annulatus del lote de reproductores del CIAD. Se 
induce a las hembras que presentan un tamaño mínimo de ovocitos de $0,5 \mathrm{~mm}$ y con el núcleo situado cerca del micrópilo; la dosis se aplica según el peso de la hembra seleccionada (50 $\mu \mathrm{g}<1000 \mathrm{~g}, 75 \mu \mathrm{g}=1000 \mathrm{~g}, 100 \mu \mathrm{g}>1000 \mathrm{~g}$ ). Las hembras producen 1,246,845 \pm 130,090 huevos por $\mathrm{kg}$ de peso (Abdo \& Duncan 2002, Abdo de la Parra et al. 2010, Duncan \& Abdo 2002, Chávez-Sánchez et al. 2008, García-Aguilar et al. 2009, Rodríguez-Ibarra et al. 2010a, 2011).

\section{FERTILIZACIÓN, DESCRIPCión DE LOS HUEVOS FERTILIZADOS Y DESARROLLO EMBRIONARIO}

Para llevar a cabo la fertilización artificial, los huevos se extraen de las hembras inducidas aplicando presión abdominal y se colocan en recipientes limpios y secos; los espermatozoides también se extraen por presión abdominal y se colectan por medio de jeringas estériles. Para fertilizar entre 10 a 20 g de huevos se añade un mililitro de esperma y $500 \mathrm{ml}$ de agua de mar esterilizada con UV y se mezcla suavemente durante un minuto. Posteriormente se elimina el exceso de líquido y se añade agua nuevamente para enjuagarlos. Los porcentajes de fertilización obtenidos son de $97 \pm 2 \%$. Los huevos fertilizados de $S$. annulatus son esféricos, miden alrededor de 0,7 \pm 0,03 mm de diámetro. Son demersales, transparentes y poseen una capa adherente. El saco vitelino contiene varias gotas pequeñas de aceite (Abdo de la Parra et al. 2001, 2010, 2012, Martínez-Palacios et al. 2002, Abdo \& Duncan 2002, Rodríguez-Ibarra et al. 2010a, 2011, 2012). Martínez-Chávez et al. (2003) demostraron que no hay diferencia en la calidad de los huevos procedentes de hembras silvestres o en cautiverio, en cuanto al porcentaje de fertilización, tamaño de los huevos y porcentaje de eclosión, mantenidas bajo las condiciones que dichos autores mencionan. El desarrollo embrionario fue descrito por Duncan et al. (2002) ${ }^{1}$ y Martínez-Palacios et al. (2002). Los huevos fertilizados se adhirieron a portaobjetos y se observaron bajo un microscopio ocular para describir el desarrollo embrionario y tomar fotografías. La primera división celular ocurre 1:18 horas después de la fertilización (HDF). A las 3:35 HDF se forma el blastómero. La notocorda se observa a las 9:40 HDF. La cabeza y la cola se distinguen a la 13:53 HDF. A las 21:29 HDF el embrión aumenta de talla y son visibles algunas vértebras alrededor del tubo neural. Después de las 27 HDF se observan los primeros movimientos del embrión y se aprecian algunos melanóforos en la superficie ventral del embrión. El corazón se observó latir desde las 51 HDF. Los ojos se observan pigmentados a partir de las 68 HDF y las vértebras cubren completamente la longitud del tubo neural. A las 76 HDF da inicio la eclosión.

\section{ELIMINACIÓN DE LA CAPA ADHERENTE DEL HUEVO}

Como ya se mencionó, los huevos fertilizados del botete poseen una capa adhesiva translúcida alrededor del corion compuesta principalmente por proteínas y azúcares (Woynarovich \& Horvath 1980, Sikkel 1990, Fujita \& Honma 1991), que sirve para que los huevos se adhieran a determinados sustratos. En los primeros protocolos de incubación del botete diana, los huevos eran sembrados en placas de vidrio (Abdo-de la Parra \& Duncan 2002, Komar et al. 2004), pero se adherían unos a otros formando masas sólidas, provocando altas mortalidades por anoxia y/o por la presencia de agentes patógenos como hongos y bacterias (Rodríguez-Ibarra et al. 2009, Rodríguez-Ibarra et al. 2010a).

En especies como la carpa, bagre y el esturión que son cultivadas con éxito en el mundo, se han desarrollado técnicas para el mejoramiento de gametos, a fin de garantizar la obtención de una gran cantidad de larvas (Kowtal et al. 1986, Gela et al. 2003, Demska-Zakés et al. 2005). Entre estas técnicas se encuentra la eliminación de la capa adherente de los huevos, utilizando productos químicos (enzimas, sales, ácido) y naturales (frutas, arcilla, leche, talco), muy efectivas para disminuir y/o eliminar la adherencia de huevos de peces dulceacuícolas (Billard et al. 1995, Gela et al. 2003, Linhart et al. 2003, Linhart et al. 2004, Thai \& Ngo 2004, Demska-Zakés et al. 2005, Linhart et al. 2006). Estas técnicas se estandarizaron para poder aplicarlas en huevos de botete diana (Rodríguez-Ibarra et al. 2010a), ya que por ser una especie de origen marino posee características diferentes a las especies dulceacuícolas antes mencionadas (tamaño, tiempo de incubación, etc.); por lo que el proceso de incubación debe manejarse de diferente manera.

En relación a los productos químicos aplicados, se determinó que los mejores porcentajes de eclosión se obtuvieron con la enzima proteolítica proteasa y el ácido tánico, métodos sencillos y rápidos de aplicar (RodríguezIbarra et al. 2009, Rodríguez-Ibarra et al. 2013). En el caso

${ }^{1}$ Duncan JN, C Komar \& N García-Aguilar. 2002. Egg and embryo development in the bullseye puffer Sphoeroides annulatus. Abstracts of the World Aquaculture, p. 198. Beijing. 
del ácido tánico se ha observado que hay que manejarlo con mucho cuidado debido a su toxicidad ya que puede dañar al embrión cuando se hace una sobreexposición de los huevos; por lo tanto no es muy recomendable su uso (Woynarovich 1983, Thai \& Ngo 2004, Demska-Zakés et al. 2005, Rodríguez-Ibarra et al. 2010a, Rodríguez-Ibarra \& Abdo-de la Parra 2012). Los métodos para eliminar la capa adherente aplicados a los huevos de botete diana han mejorado el proceso de incubación dentro del protocolo del cultivo larvario de esta especie y se ha reflejado en los elevados porcentajes de eclosión (96,47 $\pm 2,03 \%$ ) y supervivencia larvaria $(19,34 \pm 1,98 \%)$ hasta el día 45 después de la eclosión (DE), en particular cuando los huevos son desgomados con la enzima proteasa (Rodríguez-Ibarra et al. 2010a, 2013).

La aplicación de productos naturales en el desgomado de huevos de botete diana ha traído beneficios, tanto al manejo de los huevos, como en los costos de la producción de larvas. Los productos que se utilizaron fueron arcilla, leche, talco, piña y papaya; sin embargo, sólo los 2 últimos lograron eliminar la adherencia de los huevos, debido a las abundantes enzimas que contienen dichos frutos (bromelina y papaína, respectivamente), que desnaturalizan los compuestos proteicos que recubren el corion del huevo, eliminando así su adherencia (LópezLago et al. 1996, Thai \& Ngo 2004, Rodríguez-Ibarra et al. 2009, Rodríguez-Ibarra et al. 2010a).

Se ha demostrado que al usar estas técnicas para desgomar los huevos de botete diana, el tiempo de incubación disminuye ya que las larvas eclosionan antes de las 72 HPF; Rodríguez-Ibarra et al. (2013) evaluaron el efecto del desgomado de huevos con enzima proteolítica y jugo de piña en el crecimiento y supervivencia de las larvas de botete diana y observaron que las larvas eclosionaron a las $60 \mathrm{HPF}$, presentaron ausencia de pigmentos y poco movimiento; sin embargo, el desgomado de los huevos, no afectó el crecimiento de las larvas y se logró aumentar la supervivencia de las larvas a 19\% hasta el final del cultivo larvario (45 DDE), lo que representa uno los mayores logros obtenidos hasta la fecha en el desarrollo de la biotecnología del cultivo larvario de esta especie.

\section{DESINFECCIÓN DE HUEVOS}

El uso de desinfectantes durante la incubación intensiva de huevos de peces es primordial, ya que reducen la carga bacteriana presente y evita mortalidad de los embriones durante este periodo, aumentando los porcentajes de eclosión y supervivencia larvaria. Rodríguez-Ibarra et al.
(2011) evaluaron la acriflavina, formalina y glutaraldehído como agentes desinfectantes en huevos de botete diana; y concluyeron que no es recomendable el uso de desinfectantes en huevos desgomados de botete diana, ya que al eliminar la capa adherente, el corion queda más delgado y por lo tanto, es más sensible al efecto del desinfectante, causando altas mortalidades en los embriones, disminuyendo el porcentaje de eclosión (Rodríguez-Ibarra \& Abdo-de la Parra 2012).

\section{INCUBACIÓN EN JARRAS MCDONALD}

Dentro de la optimización de métodos de incubación de huevos de botete diana, se evaluó el uso de las jarras McDonald, con resultados positivos, registrándose porcentajes de eclosión más altos que los que se obtienen con los tanques de fibra de vidrio, que desde los inicios del cultivo de esta especie ha sido utilizados en las instalaciones del CIAD (Rodríguez-Ibarra et al. 2010a, b). Las jarras McDonald son un sistema de incubación para especies dulceacuícolas como la carpa, bagre y tenca donde los huevos son previamente tratados con químicos para disolver la membrana adhesiva (Thai \& Ngo 2004, Linhart et al. 2004, Carral et al. 2006) al igual que los huevos del botete diana, por lo tanto, este tipo de incubación es muy eficiente y económica ya que se pueden incubar gran cantidad de huevos en un espacio muy reducido.

EFECTO DE LA TEMPERATURA, SALINIDAD, AIREACIÓN Y TRATAMIENTO DEL AGUA EN LA INCUBACIÓN DE HUEVOS

En el agua para la incubación de huevos de botete diana se evaluó experimentalmente el efecto de diferentes temperaturas $\left(22,25,28 \mathrm{y} 31^{\circ} \mathrm{C}\right)$ y salinidades (entre $0 \mathrm{y}$ 60 , con intervalos de 5 . Se determinó que a $22^{\circ} \mathrm{C}$ el embrión no logró desarrollarse; a $31^{\circ} \mathrm{C}$ la eclosión inició a las 48 HPF; sin embargo, las larvas eclosionadas estaban deformes, manifestando encorvamiento de la notocorda y ojos sin pigmentar; en el resto de los tratamientos, la eclosión se inició a las $72 \mathrm{HDF}$, pero a $25^{\circ} \mathrm{C}$ el porcentaje de eclosión fue muy bajo (20\%). El mayor porcentaje de eclosión de larvas normales se obtuvo a $28^{\circ} \mathrm{C}$. La salinidad también tuvo un efecto sobre el desarrollo embrionario del botete diana, a 0, 50, 55 y 60 los embriones no se desarrollaron, a salinidad 5 las larvas eclosionadas no sobrevivieron al entrar en contacto con el agua y los mejores porcentajes de eclosión se obtuvieron entre 25 y 35 . Se concluyó que la temperatura y salinidad del agua pueden afectar el tiempo de incubación, desarrollo embrionario y supervivencia de las larvas recién 
eclosionadas del botete diana (Abdo de la Parra et al. 2012).

Komar et al. (2004) realizaron un experimento para determinar el efecto de la aireación y tratamiento del agua en la incubación de huevos sin desgomar de botete diana y demostraron que el porcentaje de eclosión larvaria se incrementa al incubar los huevos con aireación constante y en agua filtrada a través de un filtro de $5 \mu \mathrm{m}$ y expuesta a dos lámparas de UV.

\section{Cultivo de Alimento vivo}

Para llevar a cabo la larvicultura del botete diana es necesario contar con cultivos paralelos de alimento vivo como microalgas (Nannochloropsis oculata e Isochrysis sp.), rotíferos (Brachionus rotundiformis) y Artemia sp. Las microalgas fueron cultivadas en el laboratorio de alimento vivo del CIAD-Mazatlán, por medio de inóculos sucesivos. Las cepas se mantuvieron en tubos de ensayo y se escalonó a partir de los tubos, a matraces de $250 \mathrm{~mL}$, posteriormente a matraces de $2 \mathrm{~L}$ y luego a garrafones de 20 L, bajo condiciones controladas de luz (iluminación continua con lámparas de luz de día) temperatura (20 \pm $1^{\circ} \mathrm{C}$ ) y salinidad (34-35), usando como medio el F/2 (Guillard 1975). Los garrafones se sembraron al exterior en columnas de $80 \mathrm{~L}$, a partir de que se sembraron columnas de $700 \mathrm{~L}$, para finalmente sembrar tanques de $7000 \mathrm{~L}$. A partir de la etapa en garrafón, todos los cultivos llevaron aireación continua. Los tanques de microalgas fueron cosechados para alimentar rotíferos y para mantener el cultivo de larvas en agua verde. Los rotíferos Brachionus rotundiformis fueron cultivados también por inóculos sucesivos. La cepa se mantuvo en matraces de $1 \mathrm{~L}$ a una temperatura de $25 \pm 1^{\circ} \mathrm{C}$ y el cultivo se escalonó a partir de los matraces, sembrando en garrafones de $20 \mathrm{~L}$ a temperatura ambiente en tanques de $200 \mathrm{~L}$ para finalmente sembrar nuevamente en tanques cilindrocónicos de 1200 L. Los rotíferos fueron alimentados con la microalga Nannochloropsis oculata (15-30 x $10^{6}$ células $\left.\mathrm{mL}^{-1}\right)$. Cuando los cultivos alcanzaron densidades superiores a los 100 rotíferos $\mathrm{mL}^{-1}$, fueron cosechados, luego el producto se enjuaga y filtra a través de un tamiz de $35 \mathrm{~mm}$ de luz de malla, para ser resembrados o bien utilizados para alimentar las larvas de botete (Abdode la Parra et al. 2010, Abdo-de la Parra et al. 2011). Por otro lado, Artemia sp. no fue cultivada en las instalaciones de larvicultura de peces marinos del CIAD Mazatlán, sino que se obtiene eclosionando los quistes que facilita el mercado comercial y los nauplios se cosechan y enriquecen siguiendo las indicaciones de Velasco-Blanco \& Abdo-de la Parra (2013).

\section{LARVICULTURA A ESCALA EXPERIMENTAL}

La larvicultura a escala experimental (Tabla 1) se realiza en tanques circulares de fibra de vidrio de color negro con una capacidad de $600 \mathrm{~L}$, con un drenaje central al cual se le coloca un tubo de pvc de $50 \mathrm{~mm}$ cubierto con malla para evitar la salida de los peces y a la vez permitir la limpieza del tanque. Cada uno cuenta con aireación y suministro de agua continuos y regulables en forma independiente; el agua de mar se bombeó desde la playa Brujas de Mazatlán y es filtrada a través de filtros de arena con capacidad de retención de partículas de $16 \mu \mathrm{m}$ de diámetro y por un sistema de irradiación UV de flujo continuo con una potencia mínima de emisión de $60 \mathrm{~mJ}$ $\mathrm{cm}^{2}$. Los primeros experimentos para desarrollar los protocolos para la larvicultura se llevaron a cabo con huevos sin desgomar, adheridos a placas de vidrio que se colocaban en los tanques descritos, en sistemas estáticos; es decir, sin recambio de agua. Las larvas eclosionaron a las 72 HPF y midieron entre 1,98 a 2,08 mm de longitud total (LT). El cultivo larvario se llevó a cabo con la técnica de agua verde incluyendo 100,000 células $\mathrm{ml}^{-1}$ de Nannochloropsis oculata e Isochrysis sp. desde el día 0 hasta el día 11 DE. Las larvas se alimentaron con rotíferos Brachionus rotundiformis (5 a $10 \mathrm{ml}^{-1}$ ) a partir del día 2 hasta el día $26 \mathrm{DE}$; del día 21 al 34 DE se les suministraron 0,1 a 1 nauplios de Artemia $\mathrm{ml}^{-1}$. El destete se realizó a partir del día $29 \mathrm{DE}$ con una dieta experimental. La supervivencia obtenida fue de 1,0\% y a los 34 días después de la eclosión (DDE) midieron 18,2 \pm 0,8 mm (Abdo de la Parra et al. 2001, 2010, García-Ortega et al. 2003).

Actualmente la larvicultura (Tabla 1) a escala experimental se realiza a partir de larvas procedentes de huevos desgomados incubados en jarras McDonald (Rodríguez-Ibarra et al. 2010b, 2012), el protocolo que se sigue se describe en la Figura 1. El cultivo larvario se lleva a cabo entre 27 a $29^{\circ} \mathrm{C}$, salinidad de 33 a 35 y a una concentración de oxígeno disuelto de 4,5 a 5,0 mg L-1. En cada tanque se siembran alrededor de 31.300 larvas en aproximadamente $200 \mathrm{~L}$ de agua. Al inicio del cultivo larvario no hay flujo continuo de agua; sólo se sifonea el fondo y cada día se le añaden $50 \mathrm{~L}$ de agua hasta completar la capacidad del tanque. El flujo de agua se inicia el día 13 DE recambiando 0,2 volúmenes día ${ }^{-1}$ hasta el día $16 \mathrm{DE}$. Del día 17 al día 20 se recambian 0,5 volúmenes día ${ }^{-1}$. Del día 21 al día 30 se recambia un volumen de 0,8 a 1,0 día ${ }^{-1}$. Del día 31 a día $45 \mathrm{DE}$, el recambio aumenta de 1 a 3 volúmenes día ${ }^{-1}$. Al inicio del cultivo larvario, el flujo de aire es de $0,5 \mathrm{~L} \mathrm{~min}^{-1}$. A partir del día $16 \mathrm{DE}$ se incrementó 
Tabla 1. Comparación de los protocolos de cultivo y resultados obtenidos a través de los años en la larvicultura del botete diana (Sphoeroides annulatus) en el CIAD, Mazatlán / Comparison of culture protocols and results obtained for the bullseye puffer fish (Sphoeroides annulatus) raised over a period of time at CIAD, Mazatlán

\begin{tabular}{lcccc}
\hline & 1997 & 2001 & 2005 & 2012 \\
Fertilización de huevos & Artificial & Artificial & Artificial & Artificial \\
& $80 \pm 2,3 \%$ & $90 \pm 2,2 \%$ & $97 \pm 2,1 \%$ & $97 \pm 2,0 \%$ \\
\hline
\end{tabular}

Incubación de huevos

Cría de larvas

Alimentación de larvas

Sin definir cantidades de

Cantidad de huevos (sin $20 \mathrm{~g}$ de huevos (sin desgomar) desgomar) no conocido. tanque-1. Sistema estático con Flujo continuo con agua agua UV, aireación constante en filtrada con UV en $50 \mathrm{~L} \quad 300 \mathrm{~L}$ a $27-28^{\circ} \mathrm{C}$ $22-28^{\circ} \mathrm{C}$. rotíferos y nauplios de Artemia.

\section{Alrededor de $80 \%$}

Tanques de $300 \mathrm{~L}$ en agua esterilizada con UV, Aireación constante.

Alrededor de $80 \%$

Tanques de $600 \mathrm{~L}$ en agua verde $\left(100,000\right.$ cél. $\left.\mathrm{ml}^{-1}\right)$. Aireación constante.

5 rotíferos $\mathrm{ml}^{-1}$, Nauplios de Artemia sin enriquecer 0,5 $\mathrm{ml}^{-1}$. Destete a 29-30 DDE.
$10 \mathrm{~g}$ de huevos (sin $5 \mathrm{~g}$ de huevos desgomados en desgomar) tanque ${ }^{-1}$. Sistema jarras McDonald, con agua estático con agua UV, UV, aireación constante. 27aireación constante en $300 \mathrm{~L} 28^{\circ} \mathrm{C}$. a $27-28^{\circ} \mathrm{C}$

85 a $90 \%$

Alrededor de $97 \%$

Tanques de $600 \mathrm{~L}$ en agua Tanques de $3000 \mathrm{~L}$ en agua verde

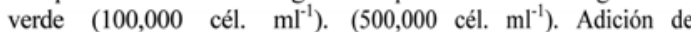
Adición de copépodos. Nauplios copépodos. Aireación constante. de Artemia enriquecidos. Mayor crecimiento.

10 rotíferos $\mathrm{ml}^{-1}, 0,5$ copépodos 20 rotíferos $\mathrm{ml}^{-1}, 0,5$ copépodos $\mathrm{ml}^{-1}$, metanauplios de Artemia $\mathrm{ml}^{-1}$, metanauplios de Artemia enriquecidos $1 \mathrm{ml}^{-1}$. Destete a los enriquecidos $4 \mathrm{ml}^{-1}$. Destete a $30 \mathrm{DDE}$. los $26 \mathrm{DDE}$.
Supervivencia a los $45 \mathrm{DDE}$

Desarrollo de las larvas
Sin datos

Sin datos
$1,0 \%$

Presencia de deformidades, hongos y enfermedad de la burbuja.

\section{$3,0 \%$}

Normal, sin presencia de hongos, mayor crecimiento al incluir copépodos, altas mortalidades al inicio de la alimentación exógena y destete.

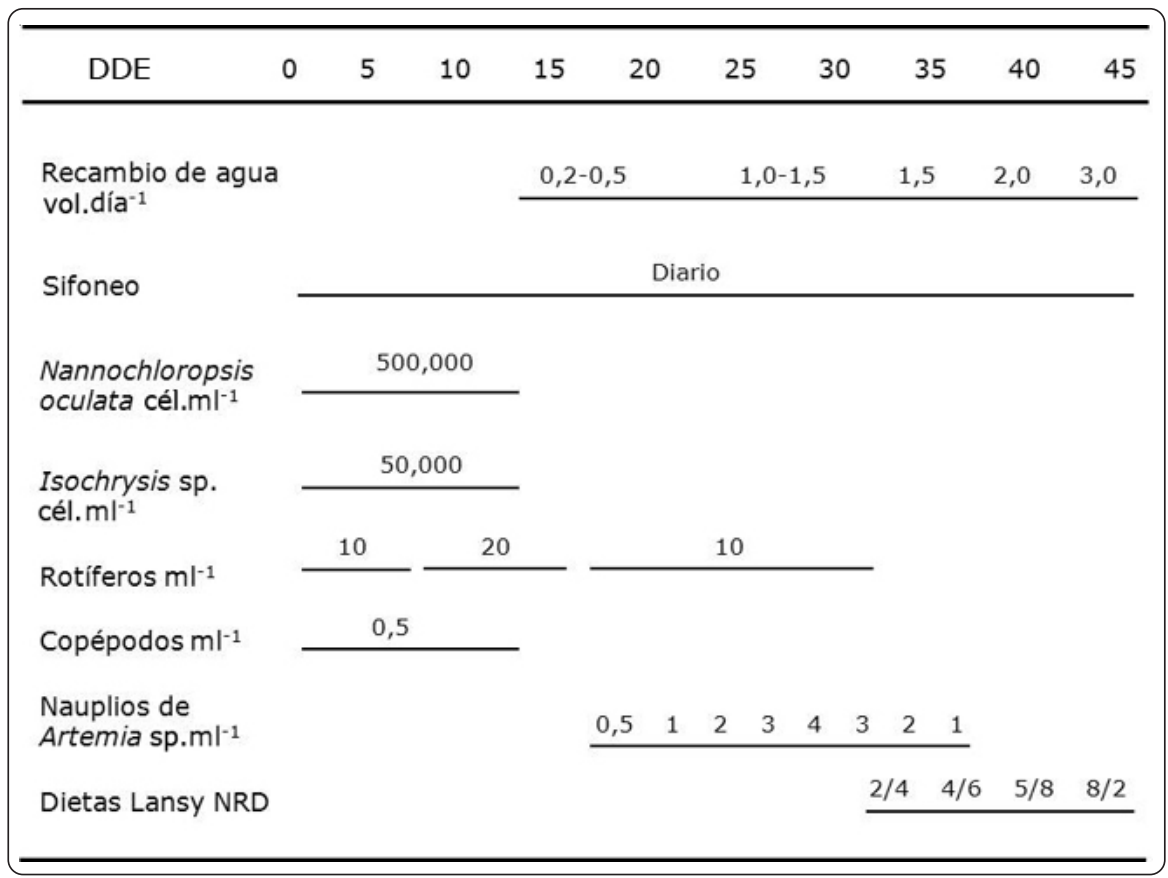

Figura 1. Protocolo de alimentación actual en el cultivo larvario del botete diana (Sphoeroides annulatus). (DDE: días después de la eclosión) / Current feeding protocols in the larvae culture of the bullseye puffer fish (Sphoeroides annulatus). (DDE: days after eclosion) 
a $1 \mathrm{~L} \mathrm{~min}^{-1}$ hasta el día 28 y a partir del inicio del destete (día 29) hasta el 45 se aumentó a $2 \mathrm{~L} \mathrm{~min}^{-1}$. Los primeros días de cultivo el fotoperiodo es de $24 \mathrm{~h}$ luz para propiciar el crecimiento de las microalgas suministradas, extender el tiempo de alimentación e incrementar el crecimiento larval. La intensidad de luz durante todo el cultivo se mantiene alrededor de 2500 lux. A partir del día 13 DE el fotoperiodo es de $12 \mathrm{~h}$ luz/12 h obscuridad (Abdo de la Parra et al. 2011). A partir del día 1 y hasta 13 DDE se añadió a los tanques de cultivo una mezcla de 500,000 células $\mathrm{ml}^{-1}$ de $N$. oculata y 50,000 células $\mathrm{ml}^{-1}$ de Isochrysis sp. Del 2 hasta 6 DDE se añaden 10 rotíferos $\mathrm{ml}^{-1}$, previamente enriquecidos con microalgas (ÁlvarezLajonchère \& Hernández-Molejón 2001). Esta cantidad aumentó a 20 rotíferos $\mathrm{ml}^{-1}$ a partir del día 7 hasta $15 \mathrm{DE}$. Además, a partir de 2 DDE se añadieron copépodos (Tisbe monozota) obtenidos del laboratorio de nutrición del CIAD (Puello Cruz et al. 2004) a una concentración de 0,5 $\mathrm{ml}^{-1}$ hasta 15 DDE. De 16 a 29 DDE la cantidad de rotíferos se redujo a $10 \mathrm{ml}^{-1}$ y se añadieron 0,5 nauplios de Artemia $\mathrm{ml}^{-1}$, y se incrementaron gradualmente hasta 4 nauplios $\mathrm{ml}^{-1}$. El alimento vivo presente en cada tanque se contó diariamente para ajustarlo a la cantidad requerida. El destete se realiza en los mismos tanques de larvicultura a partir del día $29 \mathrm{DE}$, con una dieta comercial microparticulada (Lansy 2/4, INVE Aquaculture México, Mazatlán, Sinaloa, México) para terminar el día 38 DE, reduciendo gradualmente el número de metanauplios de Artemia $\mathrm{ml}^{-1}$, hasta sustituirlos completamente por la dieta artificial (García-Ortega et al. 2003, Abdo de la Parra et al. 2011). Siguiendo este protocolo, la supervivencia a los 45 DDE aumentó de uno hasta el 15\%. Abdo-de la Parra et al. $\left(2005^{2}\right)$ demostraron que el uso de copépodos (Tisbe monozota) en la alimentación de la larvas de botete diana aumenta significativamente el crecimiento y la supervivencia de las larvas. Las larvas alimentadas con rotíferos y copépodos hasta los 21 DDE midieron 7,4 \pm $0,3 \mathrm{~mm}$ de LT y se obtuvo una supervivencia de 38,5 \pm $4,1 \%$, mientras que las alimentadas sólo con rotíferos midieron 5,2 \pm 0,4 mm de LT y una supervivencia de $21 \pm$ $6,3 \%$. Por otro lado, García-Ortega $(2007,2009)$ concluyó que al alimentar las larvas de botete diana con metanauplios de Artemia enriquecidos con ácidos grasos altamente insaturados también aumenta significativamente el crecimiento y la supervivencia de las larvas en comparación con aquellas alimentadas con nauplios de
Artemia sin enriquecer. Además, al alimentar a las larvas con Artemia enriquecida, el destete puede realizarse desde el día 22 DE, lo cual disminuye los costos de alimentación y la mano de obra necesaria para producir el alimento vivo (García-Ortega 2007, 2009).

\section{LARVICULTURA A ESCALA PILOTO}

El cultivo larvario del botete diana a escala piloto (Tabla 1) se lleva a cabo en 6 tanques circulares de fibra de vidrio con fondo blanco y paredes de color negro con una capacidad de $3000 \mathrm{~L}$, con un drenaje central, sellado con un tubo de $7,5 \mathrm{~cm}$; sobre la pared se encuentra una adaptación para recambio y se coloca un tubo de $10 \mathrm{~cm}$ ranurado y cubierto con malla fina para evitar la salida de los peces y a la vez permitir el recambio de agua. La luz de malla se cambia según el tamaño de la larva. Cada tanque cuenta con aireación y flujo de agua continuos, los cuales se regulan según se requiera (Álvarez-Lajonchere et al. 2007, 2010, 2011). El agua de mar es la misma que se utiliza para la larvicultura a escala experimental. En cada tanque se colocan alrededor de 60,000 larvas tanque ${ }^{-1}$ procedentes de la incubación de huevos desgomados en jarras McDonald (Rodríguez-Ibarra et al. 2010a y b). El cultivo larvario a escala piloto también se lleva a cabo con la técnica de agua verde; y se sigue el protocolo de alimentación descrito para la larvicultura experimental (Abdo-de la Parra et al. 2011). El cultivo se realizó a temperatura ambiente $\left(27\right.$ a $\left.30^{\circ} \mathrm{C}\right)$, la salinidad del agua oscila entre 33 a 35 y el oxígeno disuelto en el agua se mantiene a 5,0 $\mathrm{mg} \mathrm{L}^{-1}$. A escala piloto la supervivencia obtenida es de alrededor de 12\% (Álvarez-Lajonchere et al. 2011). El crecimiento es similar al obtenido por Abdo de la Parra et al. (2010, 2011).

\section{DESCRIPCIÓN Y CRECIMIENTO DE LAS LARVAS}

En la larva recién eclosionada, el saco vitelino ocupa aproximadamente el 50\% de la longitud de la larva; presentan ojos pigmentados y algunos melanóforos en la zona dorsal. Inmediatamente después de la eclosión las larvas flotan en la columna del agua sin movimiento significativo. La apertura de la boca y del tubo digestivo se observa el día 1 DE iniciándose la alimentación exógena entre los días 4 y 5 DE. Después de la absorción del saco vitelino, las larvas presentan una coloración obscura y se alimentan activamente en la columna de agua y en la

\footnotetext{
${ }^{2}$ Abdo-de la Parra MI, LE Rodríguez-Ibarra, A Puello-Cruz, B González-Rodríguez, G Velasco-Blanco, A García-Ortega, L Álvarez-Lajonchere. 2005. Evaluación del crecimiento y supervivencia de larvas de botete diana (Sphoeroides annulatus) alimentadas con copépodos (Tisbe monozota). Segundo Foro Internacional de Acuicultura. Hermosillo, Sonora.
} 
superficie (Abdo de la Parra et al. 2010). Martínez Palacios et al. (2002) realizaron la descripción larvaria hasta los 26 DDE. Las larvas recién eclosionadas miden entre 1,84 a $2,08 \mathrm{~mm}$ de LT y pesan alrededor de $24,8 \pm 1,05 \mu \mathrm{g}$ y a los $37 \mathrm{DDE}$, cuando termina el periodo de destete, miden aproximadamente 21,6 $\pm 2,94 \mathrm{~mm}$ de LT y pesan alrededor de 0,14g (Tabla 1) (Abdo \& Duncan, 2002, García-Ortega et al. 2003, Abdo de la Parra et al. 2001, 2010, 2011, Rodríguez-Ibarra et al. 2010a, 2011, Rodríguez-Ibarra \& Abdo de la Parra 2012).

\section{DENSIDAD DE SIEMBRA}

Para evaluar el efecto de la densidad de siembra sobre el crecimiento y supervivencia de larvas de botete diana, se realizó un experimento en donde se colocaron 33, 66 y 100 huevos $\mathrm{L}^{-1}$ en los tanques de $600 \mathrm{~L}$, con 3 replicados por tratamiento. Los huevos fertilizados se desgomaron según el protocolo propuesto por Rodríguez-Ibarra et al. (2010a). Se determinó el porcentaje de fertilización, porcentaje y tiempo de eclosión, LT y supervivencia de las larvas. Se concluyó que la densidad de siembra no afecta al crecimiento, pero cuando la densidad es de $66 \mathrm{y}$ 100 huevos $\mathrm{L}^{-1}$ la supervivencia de las larvas fue significativamente menor a la obtenida con una densidad de 33 huevos $\mathrm{L}^{-1}$. Los autores recomiendan realizar el cultivo larvario del botete diana con 30 huevos desgomados $\mathrm{L}^{-1}$ para disponer de una mayor cantidad de tanques sembrados por desove y aumentar la producción de juveniles (Abdo-de la Parra et al. 2011).

\section{FOTOPERIODO EN LARVICULTURA}

Estudios preliminares mostraron que el fotoperiodo influye en el crecimiento y supervivencia de las larvas del botete diana. Las larvas cultivadas con $12 \mathrm{~h}$ de luz crecieron significativamente mejor que las larvas cultivadas con 18 y 24 h de luz. La supervivencia fue mayor también a 12 h luz. Sin embargo, los autores recomiendan realizar más estudios al respecto, utilizando fotoperiodos más cortos como 6 h luz: 18 h obscuridad (Martínez-Chávez et al. 2009).

\section{EFECTO DEL DESGOMADO DE HUEVOS EN LA LARVICULTURA}

Para evaluar el efecto de varios métodos de desgomado sobre el crecimiento y supervivencia de larvas, RodríguezIbarra et al. (2013) llevaron a cabo el cultivo larvario a partir de huevos desgomados con enzima proteolítica proteasa y con jugo de piña; reportando una supervivencia de $19 \%$ en las larvas procedentes de huevos desgomados con enzima proteolítica. Este porcentaje de supervivencia es superior al reportado hasta entonces (Álvarez Lajonchere et al. 2008, Abdo-de la Parra et al. 2010, 2011).

\section{FisIología digestiva EN LARVAS}

García-Gasca et al. (2006) examinaron el desarrollo del tracto digestivo para evaluar la capacidad digestiva de larvas de botete diana desde la eclosión hasta 32 DDE. El desarrollo del tracto digestivo se analizó por histología y la actividad de la tripsina, mediante histoquímica. Se observó que el intestino y el hígado empezaron a desarrollarse en el día $1 \mathrm{DE}$, seguido por el páncreas. La actividad de la tripsina se detectó en el día 2 DE; la expresión y actividad máxima se observaron del día 16 a $24 \mathrm{DE}$, que corresponde con el período de alimentación de nauplios de Artemia. No se observaron glándulas gástricas durante todo el periodo de estudio. A partir del día 28 DE, cuando inicia el destete, la actividad y síntesis de la tripsina empieza a disminuir, lo cual sugiere que existen otras enzimas más importantes involucradas en la digestión del alimento artificial. Algunas características del desarrollo del tracto digestivo del botete diana son similares a otros peces marinos.

\section{Canibalismo Y SU CONTROL EN LA LARVICULTURA}

El canibalismo en las larvas de botete diana se ha observado desde el día $13 \mathrm{DE}$, los organismos de mayor talla cazan a los pequeños. Para disminuir o tratar de evitarlo, se inicia la alimentación a las 6:00 am y se hace necesario mantener las cantidades recomendadas de alimento vivo durante todo el día y del tamaño adecuado (incluyendo los alimentos artificiales) tratando de lograr una distribución espacial del mismo. En otras especies se recomienda una separación de tallas a través de separadores, pero en el botete diana no es tan fácil realizarla debido a que este pez, aún en estadios tempranos, tiende a inflarse cuando se siente amenazado por lo cual no logran pasar a través de la rendija del separador de tallas; otra opción es realizar una separación visual, se baja el nivel de agua del tanque, se concentran los organismos y se retiran los más grandes con una red de cuchara de malla fina, esta maniobra es muy laboriosa y puede estresar a las larvas, por lo que no sería recomendable; el control del canibalismo se puede lograr atendiendo las indicaciones anteriores respecto a la alimentación (Abdo de la Parra et al. en prensa) 


\section{ESTUDIOS TOXICOLÓGICOS EN LARVAS}

El botete diana posee una tetradotoxina presente en la piel y en algunos órganos como hígado, gónadas e intestino; la toxina no está presente en el músculo, por lo que el filete puede consumirse cuando se cocina apropiadamente (Nuñez-Vázquez et al. 2000). En los últimos 40 años han ocurrido 37 muertes de humanos por el consumo de botete diana (Poot-Delgado et al. 2011). Estudios en otras especies de botete han demostrado que los organismos cultivados contienen muy poca o nula concentración de la toxina, lo que demuestra que la presencia de la toxina depende de la dieta del pez en su medio ambiente natural (Matsui et al. 1982, Lin et al. 1998, Noguchi et al. 2006). Recientemente se realizó un estudio para determinar la concentración de tetradotoxina en huevos sin fertilizar, esperma, embriones, larvas, juveniles y adultos cultivados de botete diana y se concluyó que al igual que otras especies de botete en cultivo, no presentan concentraciones de la toxina que puedan poner en riesgo la salud humana (Núñez-Vázquez et al. 2012).

\section{ESTUDIOS EN PROCESO}

Uno de los principales problemas que presenta esta especie, al igual que algunas especies de su familia, es un crecimiento lento; varias investigaciones han demostrado durante la etapa de pre-engorda una tasa de crecimiento lenta (Abdo de la Parra et al. 2006, García-Ortega 2009), esto ha generado inseguridad para un desarrollo pleno de la maricultura de esta especie en México. Por lo tanto, uno de los grandes retos es acelerar dicha tasa de crecimiento, para lo cual una de las líneas de investigación actuales en el CIAD está enfocada en este importante aspecto. El crecimiento muscular es regulado negativamente por diversos factores; entre los que se encuentra el factor de diferenciación de crecimiento 8 (GDF8) también conocido como miostatina, pertenece a la familia del factor de crecimiento transformante beta (TGF- $\beta$ ) (Stewart \& Rittweger 2006, Lee 2010). En peces, la miostatina no sólo regula el crecimiento muscular, sino también otros procesos como son la regulación osmótica y la reproducción (Lee et al. 2009). Actualmente, se está realizando un estudio para entender la función de la miostatina en la regulación del crecimiento muscular en larvas y juveniles de botete diana en condiciones de cultivo o cautiverio, para posteriormente bloquear la

${ }^{3}$ García Gasca A. 2013. Investigadora del CIAD, Unidad Mzatlán miostatina y evaluar el crecimiento en larvas y juveniles (Com. pers. García-Gasca ${ }^{3}$ ).

\section{Conclusiones}

A través de los años de investigación se ha logrado la domesticación de la especie, los reproductores maduran en cautiverio, aunque se recomienda inducir hormonalmente a las hembras para la maduración final y asegurar la producción de huevos. El ciclo reproductivo se ha cerrado y actualmente se cuenta con organismos F1 y F2, que se han criado en las instalaciones del CIAD, Unidad Mazatlán para incorporarlos al banco de reproductores. Se mejoró el porcentaje de eclosión de larvas con la aplicación de métodos de desgomado e incubación de huevos; se mejoró el crecimiento de larvas al alimentarlas con copépodos y al enriquecer el alimento vivo con ácidos grasos poliinsaturados (PUFA); la supervivencia de las larvas hasta los $45 \mathrm{DDE}$ se ha incrementado de $1,0 \%$ hasta $19,0 \%$ aplicando los conocimientos adquiridos en cuanto a incubación, fotoperiodo, densidad de siembra, alimentación larvaria y destete, entre otros. Se demostró que los juveniles de botete diana producidos en cautiverio, no presentan tetradotoxina o su presencia es casi nula. La presente revisión demuestra la factibilidad de la producción masiva de juveniles de botete diana. El próximo reto será determinar la factibilidad biológica y económica para su engorda en estanques y/o jaulas

\section{Agradecimientos}

Los autores agradecen a V. Williams por su colaboración en la traducción del resumen. A Ibarra y J Huerta por su apoyo técnico.

\section{LITERATURA CITADA}

Abdo-de la Parra MI \& NJ Duncan. 2002. Avances en cultivo experimental de botete diana (Sphoeroides annulatus). Panorama Acuícola 7(2): 42-43.

Abdo-de la Parra MI, A García-Ortega, I MartínezRodríguez, B González-Rodríguez, G Velasco, C Hernández \& NJ Duncan. 2001. Larval rearing of the Mexican bullseyepuffer Sphoeroides annulatus under hatchery conditions. In: Hendry CI, G Van Stappen, MWille \& P Sorgeloos (eds). Contributed papers to Larvi’01 Fish \& Shellfsh Larviculture Symposium. European Aquaculture Society Special Publication 30: 4-7, Oostende. 
Abdo-de la Parra MI, JL Camacho, B González-Rodríguez, I Martínez-Rodríguez, C Hernández \& A GarcíaOrtega. 2006. A preliminary study on the effect of dietary protein level on growth and survival of juvenile bullseye puffer Sphoeroides annulatus. World Aquaculture 3(1): 34-37

Abdo-de la Parra MI, A García-Ortega, I MartínezRodríguez, B González-Rodríguez, G Velasco-Blanco, C Hernández \& N Duncan. 2010. An intensive rearing protocol for larvae of the bullseye puffer, Sphoeroides annulatus (Jenyns). Aquaculture Research 41: e554-e560.

Abdo-de la Parra MI, LE Rodríguez-Ibarra, G VelascoBlanco, N García-Aguilar, A Ibarra, NJ Duncan \& LS Álvarez-Lajonchère. 2011. Cultivo larvario del botete diana (Sphoeroides annulatus) en tres diferentes densidades de siembra. En: Ruiz Luna A, C Berlanga Robles \& M Betancourt Lozano (eds). Avances en acuicultura y manejo ambiental, pp. 3-106. Editorial Trillas, México.

Abdo-de la Parra MI, IE Martínez-Rodríguez, B GonzálezRodríguez, LE Rodríguez-Ibarra, N Duncan \& C Hernández. 2012. Efecto de la temperatura y salinidad del agua en la incubación de huevos de botete diana Sphoeroides annulatus. Revista de Biología Marina y Oceanografía 47(1): 147-153.

Abdo-de la Parra MI, LE Rodríguez Ibarra, EJ Fájer-Ávila, G Velasco Blanco \& LS Álvarez-Lajonchere. 2013. Reproducción y cría del pez globo mexicano (Sphoeroides annulatus). En: Castelló F \& A Avilés (eds). Piscicultura en Iberoamérica. Bases científicas y técnicas para su desarrollo. Universidad de Barcelona, Barcelona. En Prensa.

Amezcua-Linares F. 1996. Peces demersales de la plataforma continental del Pacífico central de México, 155 pp. Instituto Nacional de Ciencias del Mar y Limnología, UNAM, México.

Álvarez-Lajonchère LS \& O Hernández-Molejón. 2001. Producción de juveniles de peces estuarinos para un centro en América Latina y en el Caribe: diseño, operación y tecnologías, 424 pp. The World Aquaculture Society, Baton Rouge.

Álvarez-Lajonchère L, MA Reina, MA CamachoHernández \& S Kraul. 2007. Design of a pilot-scale tropical marine finfish hatchery for a research center at Mazatlán, México. Aquacultural Engineering 36: 81-96.

Álvarez-Lajonchère L, MC Chávez-Sánchez, MI Abdo-de la Parra, N García-Aguilar, L Ibarra-Castro, LE Rodríguez-Ibarra, G Velasco-Blanco, E Fájer-Avila \& A Ibarra. 2010. Pilot-Scale marine finfish hatchery at Mazatlán, México. World Aquaculture 41(1): 26-29; 7172.

Álvarez-Lajonchère L, MC Chávez-Sánchez, MA ReinaCáñez, MA Camacho-Hernández, MI Abdo-de la Parra, N García-Aguilar, L Ibarra-Castro, LE RodríguezIbarra, E Fájer-Avila, G Velasco-Blanco, A Puello-Cruz, B González-Rodríguez \& A Ibarra-Soto. 2011. Evolución de la escala experimental a la piloto para las tecnologías de producción de juveniles de peces marinos en la Unidad Mazatlán. En: Ruiz Luna A, C Berlanga-Robles \& M Betancourt-Lozano (eds). Avances en acuicultura y manejo ambiental, pp. 17-38. Editorial Trillas, México.

Billard R, J Cosson, G Perchec \& O Linhart. 1995. Biology of sperm and artificial reproduction in carp. Aquaculture 129: 95-112.

Carral JM, JD Celada, M Sáenz-Royuela, R Rodríguez, A Aguilera \& P Melendre. 2006. Effects of four egg desticking procedures on hatching rate and further survival and growth of larvae in the tench (Tinca tinca L.). Aquaculture 37: 632-636.

Chávez-Sánchez MC, LS Álvarez-Lajonchère, MI Abdode la Parra \& N García-Aguilar. 2008. Advances in the culture of the Mexican bullseye puffer fish Sphoeroides annulatus, Jenyns (1842). Aquaculture Research 39: 718730.

Duncan N \& I Abdo de la Parra. 2002. Marine fish specialists focus on puffer fish. World Aquaculture 33(3): 34-38.

Duncan NJ, GA Rodriguez M de O, D Alok \& Y Zohar. 2003. Effects of controlled delivery and acute injections of LHRHa on bullseye puffer fish (Sphoeroides annulatus) spawning. Aquaculture 218: 625-635.

Fájer-Ávila EJ \& MC Chávez-Sánchez. 1999. Parasites and their effect on the wild bullseye puffer fish (Sphoeroides annulatus Jenyns, 1843). Fifth International Symposium of Fish Parasites, 9-13 August 1999, Ceské Budejovice, Czech Republic, p. 186.

Fájer-Ávila EJ, MI Abdo-De la Parra, G Aguilar-Zarate, $\mathbf{R}$ Contreras-Arce, J Zaldívar-Ramírez \& M BetancourtLozano. 2003. Toxicity of formalin to bullseye puffer fish (Sphoeroides annulatus Jenyns, 1843) and its effectiveness to control ectoparasites. Aquaculture 223: 41-50

Fájer-Ávila EJ, A Roque, G Aguilar \& N Duncan. 2004. Patterns of occurrence of the platyhelminth parasites of the wild bullseye puffer (Sphoeroides annulatus) of Sinaloa, México. Journal of Parasitology 90: 415-418.

Fájer-Ávila EJ, I Martínez, MI Abdo de la Parra, L ÁlvarezLajonchère \& M Betancourt. 2008. Effectiveness of freshwater treatment against Lepeophtheirus simplex (Copepoda: Caligidae) and Neobenedenia sp. (Monogenea: Capsalidae), skin parasites of bullseye puffer fish, Sphoeroides annulatus reared in tanks. Aquaculture 284: 1-4

Fájer-Ávila EJ, SM Abad-Rosales, RM Medina-Guerrero \& M Betancourt-Lozano. 2011. Avances sobre las investigaciones parasitológicas en el cultivo de peces marinos en Sinaloa, México. En: A Ruiz, C Berlanga \& M Betancourt (eds). Avances en acuicultura y manejo ambiental, pp. 7192 Editorial Trillas, México.

Fujita S \& Y Honma. 1991. Induction of ovarian maturation and development of eggs, larvae and juvenile of the puffer, Takifugu exascurus, reared in the laboratory. Japanese Journal of Ichthyology 38: 211-218. 
García-Aguilar N, I Abdo-de la Parra, E Rodríguez- Ibarra, L Ibarra-Castro, Z Ibarra-Zataraín \& LS ÁlvarezLajonchère. 2009. Desove de botete diana. Revista Ciencia y Desarrollo, CONACYT, México 35(23): 69.

García-Gasca A, MA Galaviz, JN Gutiérrez \& A GarcíaOrtega. 2006. Development of the digestive tract, trypsin activity and gene expression in eggs and larvae of the bullseye pufferfish Sphoeroides annulatus. Aquaculture 251: 366-367.

García-Ortega A. 2007. Current state of research and production of bullseye puffer Sphoeroides annulatus. In: González-Félix ML, L Bringas-Alvarado, M PérezVelázquez \& S Meza-García (eds). Proceedings of the 3rd International Aquaculture Forum, pp. 58-83. Hermosillo, México.

García-Ortega A. 2009. Nutrition and feeding research in spotted rose snapper (Lutjanus guttatus) and bullseye puffer (Sphoeroides annulatus), new species for marine aquaculture. Fish Physiology and Biochemistry 36: 69-80.

García-Ortega A, I Abdo \& C Hernández. 2003. Weaning of bullseye puffer (Sphoeroides annulatus) from live food to microparticulate diets made with decapsulated cysts of Artemia and fishmeal. Aquaculture International 11: 183194.

Gela D, O Linhart, M Flajšhans \& M Rodina. 2003. Egg incubation time and hatching success in tench Tinca tinca (L.) related to the procedure of egg stickiness elimination. Journal of Applied Ichthyology 19: 132-133.

Ho J, S Gómez \& EJ Fájer-Ávila. 2001. Lepeophtheirus simplex sp. a caligid copepod (Siphonostomatoida) parasitic on "botete" (bullseye puffer, Sphoeroides annulatus) in Sinaloa, México. Folia Parasitic 48: 240-248.

Kanazawa A. 1991. Puffer fish, Fugu rubipres. In: Wilson RP (ed). Handbook of nutrients requirements of finfish, pp. 123-129. CRC Press, Boca Raton.

Komar C, JF Turnbull, A Roque, E Fajer \& NJ Duncan. 2004. Effect of water treatment and aeration on the percentage hatch of demersal, adhesive eggs of the bullseye puffer (Sphoeroides annulatus). Aquaculture 229: 147-158.

Kowtal GV, WH Clark Jr \& GN Cherr. 1986. Elimination of adhesiveness in eggs from the white sturgeon, Acipenser transmontanus: chemical treatment of fertilized eggs. Aquaculture 55: 139-143.

Lee CY, SY Hu, HY Gong, MHC Chen, JK Lu \& JL Wu. 2009. Suppression of myostatin with vector-based RNA interference causes a double-muscle effect in transgenic zebrafish. Biochemical and Biophysical Research Communications 387: 766-771.

Lee SJ. 2010. Extracellular regulation of Myostatin: A molecular rheostat for muscle mass. Immunology, Endocrine \& Metabolic Agents in Medicinal Chemistry 10: 183-194.

Lin SI, T Chai, SS Jung \& DF Hwang. 1998. Toxicity of the puffer Takifugu rubripes cultured in northern Taiwan. Fisheries Science 64: 766-770.
Linhart O, M Rodina, D Gela, M Flajšhans \& M Kocour. 2003. Enzyme treatment for elimination of egg stickiness in tench (Tinca tinca L.), European catfish (Silurus glanis L.) and common carp (Cyprinus carpio L.). Fish Physiology and Biochemistry 28: 507-508.

Linhart O, D Gela, M Rodina \& M Kocour. 2004. Optimization of artificial propagation in European catfish, Silurus glanis L. Aquaculture 235: 619-632.

Linhart O, M Rodina M Kocour \& D Gela. 2006. Insemination, fertilization and management in tench, Tinca tinca (L.). Aquaculture 14: 61-73.

López-Lago I, J Díaz-Varela \& F Merino de Cáceres. 1996. La bromelina: Una proteasa de interés comercial. Ciencia y Tecnología Alimentaria 1(2): 17-22.

Mallard CL, A Yáñez-Arancibia \& F Amezcua-Linares. 1982. Taxonomía, biología y ecología de los Tetraodóntidos de la laguna de Términos, sur del golfo de México (Pises: Tetraodontidae). Anales del Instituto de Ciencias del Mar y Limnología, Universidad Nacional Autónoma de México 9(1): 161-212.

Mártinez-Chávez C, N García-Aguilar \& NJ Duncan. 2003. Comparison of egg quality between wild and captive bullseye puffer (Sphoeroides annulatus). Fish Physiology and Biochemistry 28: 509-510.

Martínez-Palacios C, C Chávez-Sánchez, S Papp, MI Abdode la Parra \& L Ross. 2002. Observations on spawning, early development and growth of the puffer fish Sphoeroides annulatus (Jenyns, 1843). Journal of Aquaculture in the Tropics 17(1): 59-66.

Matsui T, H Sato, S Hamada \& C Shimizu. 1982. Comparison of toxicity of the cultured and wild puffer fish Fugu niphobles. Bulletin of the Japanese Society of Scientific Fisheries 48: 253.

Noguchi T, O Arakawa \& T Takatani. 2006. Toxicity of pufferfish Takifugu rubripes cultured in netcages at sea or aquaria on land. Comparative Biochemistry Physiology Part D 1: 153-157.

Núñez-Vázquez EJ, M Yotsu-Yamashita, AP SierraBeltrán, T Yasumoto \& JL Ochoa. 2000. Toxicities and distribution of tetrodotoxin in the tissues of puffer fish found in the coast of the Baja California Peninsula, México. Toxicon 38: 729-734.

Poot-Delgado CA, EJ Núñez-Vázquez \& AJ Ruiz-Ibáñez. 2011. Intoxicaciones humanas por consumo de peces botete (Tetraodontidae) en Campeche, México. En: Secretaria de Educación Pública (ed). Proceedings in extenso. Congreso Nacional de Ciencias y Tecnología del Mar, Secretaria de Educación Pública; Nuevo Guaymas, México. 7-9 September 2011. <http://www.academia.edu/4499645/ Intoxicaciones_humanas>

Puello-Cruz AC, B González-Rodríguez, A García-Ortega \& S Gómez. 2004. Use of a tropical harpacticoid copepod Tisbe monozota Bowman, 1962 (Copepoda:Harpacticoida: 
Tisbidae) as live food in marine larviculture. In: Hendrickx ME (ed). Contributions to the Study of East Pacific Crustaceans 3, pp. 177-187. ICMyL, UNAM, México.

Rodríguez-Ibarra LE \& MI Abdo-de la Parra. 2012. Desgomado, desinfección e incubación de huevos de botete diana: Optimización de métodos para la obtención de larvas de botete diana (Sphoeroides annulatus), 64 pp. LAP LAMBERT Academic Publishing, Saarbrücken.

Rodríguez-Ibarra LE, GA Rodríguez-Montes de O, CY Padilla-Aguiar, VP Domínguez-Jiménez, MA SánchezRodríguez, G Velasco-Blanco \& N García-Aguilar. 2009. Aplicación de productos naturales y químicos para desgomar los huevos de botete diana Sphoeroides annulatus. Industria Acuícola 5(6): 13-15.

Rodríguez-Ibarra LE, MI Abdo-de la Parra, GA RodríguezMontes de Oca, MS Moreno-Hernández, G VelascoBlanco, N García-Aguilar \& LS Álvarez-Lajonchère. 2010a. Evaluación de métodos para la eliminación de la capa adherente de los huevos del botete diana Sphoeroides annulatus (Jenyns, 1842). Revista de Biología Marina y Oceanografía 45(1): 147-151.

Rodríguez Ibarra LE, GA Rodríguez-Montes De Oca, CY Padilla-Aguilar, VY Zepeda-Mercado \& G VelascoBlanco. 2010b. Evaluación de dos métodos de incubación de huevos de botete diana Sphoeroides annulatus. Industria Acuícola 6(5): 4-7.

Rodríguez-Ibarra LE, MI Abdo-de la Parra, GA RodríguezMontes de Oca, CY Padilla-Aguiar, VY ZepedaMercado, G Velasco-Blanco \& N García-Aguilar. 2011. Efecto de la acriflavina, formalina y glutaraldehído sobre la desinfección y la eclosión de los huevos del botete diana Sphoeroides annulatus. Revista de Biología Marina y Oceanografía 46(1): 59-65.
Rodríguez-Ibarra LE, MI Abdo-de la Parra, G VelascoBlanco, BT González-Rodríguez, VP DomínguezJiménez, N García-Aguilar \& L Ibarra-Castro. 2013. Efecto de la eliminación de la capa adherente de los huevos utilizando enzima proteolítica proteasa y jugo de piña en la larvicultura del botete diana Sphoeroides annulatus. Revista de Biología Marina y Oceanografía 48(2): 379-385.

Rodríguez-Montes de Oca G. 2001. Evaluación de la calidad del esperma del botete diana (Sphoeroides annulatus) en condiciones de cautiverio y bajo inducción hormonal con LHRHa. Tesis de Maestría en Ciencias, Centro de Investigación en Alimentación y Desarrollo, Unidad Mazatlán, México, 129 pp.

Sikkel PC. 1990. Social organization and spawning in the Atlantic sharpnose puffer, Canthigaster rostrata. Environmental Biology of Fishes 27: 243-254.

Stewart CEH \& J Rittweger. 2006. Adaptive processes in skeletal muscle: Molecular regulators and genetic influences. Journal Musculoskeletal and Neuronal Interactions 6: 7386.

Thai BT \& TG Ngo. 2004. Use of pineapple juice for elimination of egg stickiness of common carp (Cyprinus carpio L.). Asian Fisheries Science 17: 159-162.

Thomson D, L Findley \& NA Kerstitch. 2000. Reef fishes of the sea of Cortez. The rocky-shore fishes of the golf of California, 353 pp. University of Texas Press, Austin.

Tucker JW. 1998. Marine fish culture, 750 pp. Kluwer Academic Publishers, Massachusetts.

Velasco-Blanco G \& MI Abdo de la Parra. 2013. Cultivo de alimento vivo para la maricultura, $67 \mathrm{pp}$. LAP LAMBERT Academic Publishing, Saarbrücken.

Woynarovich E. 1983. Artificial propagation of Clarias lazera at the Fish Culture Centre Hatchery, Bangui-Landjia. A report prepared for the Hatchery Production and Research Centre Project. FAO GCP/CAF/007/NET- Field Document 1: 1-7.

Recibido el 10 de abril 2013 y aceptado el 5 de agosto de 2013

Editor: Claudia Bustos D. 